\title{
Determination of lipophilicity of some new 1,2,4-triazole derivatives by RP-HPLC and RP-TLC and calculated methods
}

\author{
Anna M. Hawrył ${ }^{* a}$, Ryszard S. Świeboda ${ }^{a}$, Mateusz S. Gawrońskia ${ }^{a}$ Magdalena A. Wójciak- \\ Kosior $^{\mathrm{b}}$, Lukasz P. Popiołek ${ }^{\mathrm{c}}$ and Ryszard B. Kocjan ${ }^{\mathrm{b}}$
}

${ }^{a}$ Department of Inorganic Chemistry, Medical University of Lublin, Chodźki 4a, 20-093 Lublin, Poland ${ }^{b}$ Department of Analytical Chemistry, Medical University of Lublin, Chodźki 4a, 20-093 Lublin, Poland 'Department of Organic Chemistry, Medical University of Lublin, Chodźki 4a, 20-093 Lublin, Poland

\begin{tabular}{l}
\hline C H R O N I C L E \\
\hline Article history: \\
Received January 21, 2015 \\
Received in revised form \\
March 29, 2015 \\
Accepted 28 April 2015 \\
Available online \\
29 April 2015 \\
\hline Keywords: \\
lipophilicity \\
1,2,4-triazole derivatives \\
Computed logP \\
RP-HPLC \\
RP-TLC \\
PCA \\
\hline
\end{tabular}
\begin{abstract}
A B S T R A C T
Experimental and computational approaches were used to estimate the lipophilicity of novel 1,2,4-triazole derivatives. These derivatives have been subjected to this research, because they exhibit antimicrobial activity. The chromatographic analysis of RP-HPLC and RP-TLC was carried out using methanol-water or acetonitrile-water as mobile phase. The linear relationships between $\log k$ (or $R_{M}$ ) values and the concentration of organic modifier were obtained. The lipophilicity was expressed as chromatographically derived descriptors: $\log k_{W}, S$, $\varphi_{0}$ and scores $\log k$ and $R_{M}$ corresponding to the first principal component. The experimental lipophilicity data have been compared with the computer calculated lipophilicity parameters (milogP, clogP, ALOGPS, AClogP, AlogP, MLOGP, KOWWIN, XLOGP2, XLOGP3, $\log P_{C h S}$ ) of the same molecules. The matrices were created with $\log k_{W}$ or $R_{M}^{0}$ and $\log P$ and they have been the subject of PCA analysis.
\end{abstract}

(c) 2015 Growing Science Ltd. All rights reserved.

\section{Introduction}

Molecular transport through lipid membranes (intestinal absorption, blood-brain barrier penetration) of potential drugs is directly related to their chemical and physical properties. The most important properties are lipophilicity, number of hydrogen bonds, surface properties ${ }^{1}$.

Lipophlicity is well-known as a prime physic-chemical descriptor of drug (potential drug) with relevance to their biological properties. It plays the main role in the control of pharmacokinetic and pharmacodynamic properties of biological active compounds. Lipophilicity is usually expressed as a partition coefficient $(P)$ or its decimal logarithm $(\log P)$ between a non-aqueous and aqueous phase ${ }^{2}$. The determination of partition coefficient using the shake flask equilibration method is associated with

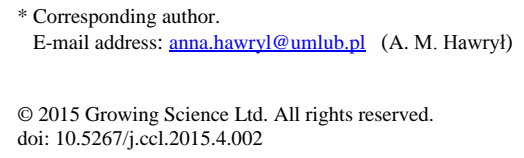


many problems (poor reproducibility, time consuming experiments, high purity of analytes is required). The reversed-phase HPLC or TLC are very popular alternative methods in $\log P$ determined due to its high-throughput, small amount of solutes needed and a wide applicable range. In case of HPLC method the lipophilicity index is derived from the retention factor $\log k$ and in case of TLC method from $R_{M}$ values. The extrapolatedlog $k$ and $R_{M}$ values at pure water as mobile phase $\left(\log k_{W}, R_{M}^{0}\right)$ were used as the lipophilicity parameters. Both HPLC and TLC methods are used to determine the lipophilicity and to predict the relationship between molecular structure and its biological activity ${ }^{3-7}$. A linear relationships between the retention parameters and the concentration $(\varphi)$ of organic modifier in the aqueous mobile phase has to be established for chromatographic measurement of lipophilicity and it can be represented as the dependence (1) ${ }^{8}$ :

$$
\log k=\log k_{W}-S \varphi
$$

where $\log k$ is solute retention factor at a specific mobile phase composition, $\varphi$ is the volume fraction of organic solvent in the water-organic solvent mixture, $S$ is the slope of the regression curve, the intercept $\log k_{W}$ (lipophilicity index) is the retention parameter of solutes for pure water as the eluent.

The relationship between the retention factor $\left(R_{M}\right)$ and the mobile phase composition in this case looks as follows ${ }^{9}$ :

$$
R_{M}=R_{M}^{0}-S \cdot \varphi
$$

where similarly the $R_{M}$ is the retention factor of substance. Subsequent chromatographic lipophilicity parameter is $\varphi_{0}$ for both methods respectively ${ }^{10-12}$ :

$$
\begin{aligned}
& \varphi_{0}=\frac{\log k_{W}}{S}, \\
& \varphi_{0}=\frac{R_{M}^{0}}{S},
\end{aligned}
$$

where, $\varphi_{0}$ represents the ratio of the slope and intercept of Eq. (1) and Eq. (2). The $\varphi_{0}$ parameter is the concentration of the organic modifier, which causes the $\log k$ is equal to zero, i.e. the amount of solute in the mobile phase and stationary phase are equal $(k=1)^{10}$.

In order to determine the lipophilicity properties some novel 1,2,4-triazole derivatives, the chromatographic analysis in reversed phase system was conducted. Previous studies have shown that the examined compounds show antibacterial activity ${ }^{13,14}$. The inhibitory activities against Grampositive bacteria on the basis of minimal inhibitory concentration (MIC, $\mu \mathrm{g} / \mathrm{mL}$ ) values showing the following compounds: $\mathbf{6 , 7 , 8 , 9 , 1 0}$ and $\mathbf{1 6 , 1 8}{ }^{13,14}$.

The aim of this work was the determination of lipophilicity of the 1,2,4-triazole derivatives by RPHPLC and RP-TLC methods ( $\log k_{W}$ or $R_{M}^{0}, S, \varphi_{0}$ and the scores corresponding to the first principal components of $k$ and $\log k_{W}$ or $R_{M}$ and $R_{M}^{0}$ values) and using different calculation methods (milogP, $c \log P, A \log P s, A C \log P, A \log P, M \log P, K O W W I N, X \log P 2, X \log P 3 a n d \log P C h s){ }^{15-17} . M i \log P 1.2$ software calculates $\log \mathrm{P}$ values as the sum of group contribution and correlation factors $(\operatorname{milog} P$ parameter) ${ }^{15,18}$. These have been obtained by fitting calculated $\log P$ with experimental $\log P$ for a training set more than twelve thousand, mostly drug-like molecules.

In this way hydrophobicity values for 35 small simple "basic" fragments have been obtained, as well as values for 185 larger fragments, characterizing intramolecular hydrogen bonding contribution to 
$\log P$ and charge interactions. Molinspiration methodology for $\log P$ calculation is very robust and is able to process practically all organic and most organometallic molecules.

clogP calculation method is implemented as increment system adding contributions of every atom based on its atom type ${ }^{16}$. All together the $\operatorname{clog} P$ predicting engine distinguishes 368 atom types which are composed of various properties of the atom itself (atomic no and ring membership) as its direct neighbours (bond type, aromaticity state and encoded atomic no). More than 5000 compounds with experimentally determined $\log P$ values were used as training set to optimize the 369 contribution values associated with the atom types. The program ALOGPS 2.1 from Virtual Computational Chemistry Laboratory provides interactive on-line prediction of $\log P$ (ALOGPs, AClogP, AlogP, MLOGP, KOWWIN , XLOGP2, XLOGP3) ${ }^{17}$. The method is based on atom - type $\mathrm{E}$ - state indices and associative neural network modeling and was developed by Tetko et al. This method combines electronic and topological characteristics to predict the lipophilicity of the molecules analyzed.

\section{Results and discussion}

1,2,4-triazole derivatives shown in Table 1 were analyzed by RP-TLC and RP-HPLC methods using methanol-water and acetonitrile-water as mobile phases (mobile phase composition are shown in Table 2). The linear relationships between the $\log k$ (or $R_{M}$ ) values and volume fraction of methanol (or acetonitrile) were obtained in given analytical range (Table 2). The parameters of these relationships are presented in Table 3a (for methanol-water system) and Table 3b (for acetonitrile-water system). The goodness of fit the linear equation for experimental data was defined by Jaffe ${ }^{19}$. The excellent goodness of fit the linear equations (1-2) for experimental data for all compounds in methanol-water system was obtained (see Table 3a). For acetonitrile-water system, the excellent goodness of fit the Eq. (2) for experimental data in 17 out of 18 cases. In case of RP-HPLC method the correlation coefficient of the equation (1) $r>0,98$ in 12 out of 15 cases.

The values of $\log k_{W}$ and $R_{M}^{0}$ are the retention parameters of a substance in pure water (obtained by extrapolation of $\log k$ and $R_{M}$ to pure water using equations 1 and 2).

Table 1. Analyzed compounds

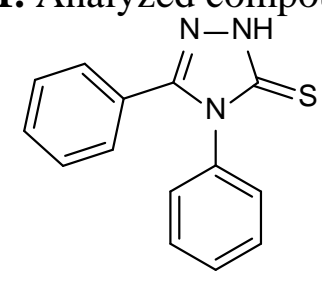

1<smiles>CCNC(=S)NNC(=O)CSc1nnc(-c2ccccc2)n1-c1ccccc1</smiles>

4<smiles>CCOC(=O)CSc1nnc(-c2ccccc2)n1-c1ccccc1</smiles>

2<smiles>O=C(CSc1nnc(-c2ccccc2)n1-c1ccccc1)NNC(=S)NCc1ccccc1</smiles>

5<smiles>NNC(=O)CSc1nnc(-c2ccccc2)n1-c1ccccc1</smiles>

3<smiles>O=C(CSc1nnc(-c2ccccc2)n1-c1ccccc1)NNC(=S)NC1CCCCC1</smiles>

6 
<smiles>CCOC(=O)CNC(=S)NNC(=O)CSc1nnc(-c2ccccc2)n1-c1ccccc1</smiles>

7<smiles></smiles>

10<smiles>S=c1[nH]nc(-c2cccnc2)n1-c1ccccc1</smiles>

13<smiles>C=CCNC(=S)NNC(=O)CSc1nnc(-c2cccnc2)n1-c1ccccc1</smiles>

16<smiles></smiles>

8<smiles>CCNc1nnc(CSc2nnc(-c3ccccc3)n2-c2ccccc2)s1</smiles>

11<smiles>CCOC(=O)CSc1nnc(-c2cccnc2)n1-c1ccccc1</smiles>

14<smiles>CCOC(=O)NC(=S)NNC(=O)CSc1nnc(-c2cccnc2)n1-c1ccccc1</smiles>

17<smiles>COc1ccc(-n2c(CSc3nnc(-c4ccccc4)n3-c3ccccc3)n[nH]c2=S)cc1</smiles>

9<smiles>C=CCn1c(CSc2nnc(-c3ccccc3)n2-c2ccccc2)n[nH]c1=S</smiles>

12<smiles>NNC(=O)CSc1nnc(-c2cccnc2)n1-c1ccccc1</smiles>

15<smiles>O=C(CSc1nnc(-c2cccnc2)n1-c1ccccc1)NNC(=S)Nc1ccc(Cl)cc1</smiles>

18

In case of HPLC method the compounds with number 7, 16 and 17 have rejected (asymmetric and wide peaks were obtained). The retention time values were ambiguous and the determination of $\log k_{W}$ parameter was subject to large error of $50 \%$.

Table 2. The solvent mixtures used as mobile phases ( $\mathrm{n}$ - number of points)

\begin{tabular}{|c|c|c|c|c|}
\hline Methods & Eluent & Compound & $\begin{array}{c}\text { Volume fraction }(\varphi, v / v) \\
\text { of organic component }\end{array}$ & $n$ \\
\hline \multirow{11}{*}{ HPLC } & \multirow{4}{*}{ Methanol- water } & $2-5,8-12,18$ & $45-70 \%$ & 6 \\
\hline & & 13 & $30-60 \%$ & 7 \\
\hline & & 14 & $40-65 \%$ & 6 \\
\hline & & 15 & $35-60 \%$ & 6 \\
\hline & \multirow{7}{*}{ Acetonitrile-water } & 1,12 & $30-65 \%$ & 8 \\
\hline & & $2,5,8-11$ & $35-65 \%$ & 7 \\
\hline & & 3,4 & $30-60 \%$ & 7 \\
\hline & & 6 & $20-45 \%$ & 6 \\
\hline & & 13,15 & $20-50 \%$ & 7 \\
\hline & & 14 & $25-50 \%$ & 6 \\
\hline & & 18 & $30-55 \%$ & 6 \\
\hline \multirow{2}{*}{ TLC } & Methanol- water & \multirow{2}{*}{$1-18$} & $55-80 \%$ & 6 \\
\hline & Acetonitrile -water & & $45-70 \%$ & 6 \\
\hline
\end{tabular}


A. M. Hawrył et al. / Current Chemistry Letters 4 (2015)

Similarities in the structure are visible for the first three pairs of compounds. The substituent $\mathrm{R}^{1}$ for the compounds $1,2,3$ is a phenyl, while the rest of compounds of analogous structure $(\mathbf{1 3}, \mathbf{1 4}, \mathbf{1 5})$ is pyridine-2-yl. The presence of nitrogen in the heterocyclic structure of the analyzed compounds (proton-acceptor properties) to increase their affinity to the polar mobile phase (mixtures of methanol and water or acetonitrile and water).

Table 3a. Parameters of the equations $(1,2)$ for methanol-water system

\begin{tabular}{|c|c|c|c|c|c|c|c|c|c|c|}
\hline \multirow[b]{2}{*}{ Compound } & \multicolumn{5}{|l|}{$T L C$} & \multicolumn{5}{|c|}{$H P L C$} \\
\hline & $R_{M}^{0}$ & $-S$ & $r$ & $n$ & $\begin{array}{c}\text { SD of } \\
\text { estimation }\end{array}$ & $\log k_{W}$ & $-S$ & $r$ & $n$ & $\begin{array}{c}\text { SD of } \\
\text { estimation }\end{array}$ \\
\hline 1 & 3.0149 & 4.3257 & 0.9912 & 6 & 0.060 & 3.0296 & 4.4929 & 0.9958 & 7 & 0.049 \\
\hline 2 & 4.0237 & 5.3314 & 0.9930 & 6 & 0.066 & 3.9510 & 5.4857 & 0.9978 & 6 & 0.038 \\
\hline 3 & 2.5090 & 3.5886 & 0.9860 & 6 & 0.064 & 3.4738 & 5.1186 & 0.9967 & 6 & 0.044 \\
\hline 4 & 2.2970 & 3.3314 & 0.9826 & 6 & 0.066 & 3.4889 & 5.1371 & 0.9969 & 6 & 0.042 \\
\hline 5 & 2.6836 & 3.7486 & 0.9679 & 6 & 0.102 & 2.8211 & 3.8629 & 0.9993 & 6 & 0.015 \\
\hline 6 & 2.1826 & 3.1371 & 0.9696 & 6 & 0.083 & 2.6546 & 4.1643 & 0.9703 & 6 & 0.121 \\
\hline 7 & 3.5202 & 4.9657 & 0.9877 & 6 & 0.082 & & & & - & - \\
\hline 8 & 3.5050 & 4.8914 & 0.9848 & 6 & 0.090 & 3.9731 & 5.8229 & 0.9957 & 6 & 0.057 \\
\hline 9 & 3.5829 & 4.8857 & 0.9807 & 6 & 0.102 & 4.0497 & 5.8343 & 0.9973 & 6 & 0.045 \\
\hline 10 & 3.2544 & 4.4114 & 0.9918 & 6 & 0.059 & 3.5570 & 5.1543 & 0.9970 & 6 & 0.042 \\
\hline 11 & 3.2200 & 4.4000 & 0.9913 & 6 & 0.061 & 3.5390 & 5.1257 & 0.9968 & 6 & 0.043 \\
\hline 12 & 3.4267 & 4.8000 & 0.9932 & 6 & 0.059 & 3.8269 & 5.5771 & 0.9966 & 6 & 0.048 \\
\hline 13 & 1.7097 & 2.8514 & 0.9977 & 6 & 0.020 & 2.4918 & 5.2071 & 0.9978 & 7 & 0.041 \\
\hline 14 & 2.6703 & 3.7486 & 0.9948 & 6 & 0.040 & 3.1420 & 5.0800 & 0.9971 & 6 & 0.041 \\
\hline 15 & 1.2935 & 2.1657 & 0.9906 & 6 & 0.031 & 3.0530 & 5.7257 & 0.9976 & 6 & 0.042 \\
\hline 16 & 2.4464 & 3.3814 & 0.9909 & 6 & 0.055 & & & - & - & - \\
\hline 17 & 2.7705 & 4.1143 & 0.9826 & 6 & 0.081 & & & - & - & - \\
\hline 18 & 3.6715 & 5.1257 & 0.9908 & 6 & 0.073 & 3.7794 & 5.6686 & 0.9954 & 6 & 0.057 \\
\hline
\end{tabular}

Table 3b.Parameters of the equations $(1,2)$ for acetonitrile-water system.

\begin{tabular}{|c|c|c|c|c|c|c|c|c|c|c|}
\hline \multirow[b]{2}{*}{ Compound } & \multicolumn{5}{|l|}{$T L C$} & \multicolumn{4}{|c|}{ HPLC } & \multirow[b]{2}{*}{$\begin{array}{c}\text { SD of } \\
\text { estimation }\end{array}$} \\
\hline & $R_{M}^{0}$ & $-S$ & $r$ & $n$ & $\begin{array}{c}\text { SD of } \\
\text { estimation }\end{array}$ & $\log k_{W}$ & $-S$ & $r$ & $n$ & \\
\hline 1 & 2.0870 & 3.7543 & 0.9998 & 6 & 0.008 & 2.0913 & 3.3722 & 0.9905 & 8 & 0.062 \\
\hline 2 & 2.3512 & 3.4514 & 0.9975 & 6 & 0.025 & 2.4858 & 3.6900 & 0.9902 & 7 & 0.062 \\
\hline 3 & 1.1462 & 2.0571 & 0.9831 & 6 & 0.040 & 2.0143 & 3.6649 & 0.9827 & 7 & 0.082 \\
\hline 4 & 1.2382 & 2.2171 & 0.9911 & 6 & 0.031 & 2.0073 & 3.6406 & 0.9820 & 7 & 0.083 \\
\hline 5 & 2.2781 & 3.6286 & 0.9908 & 6 & 0.052 & 2.2932 & 3.2139 & 0.9964 & 7 & 0.032 \\
\hline 6 & 1.2397 & 2.2343 & 0.9915 & 6 & 0.031 & 2.4652 & 5.8088 & 0.9777 & 9 & 0.132 \\
\hline 7 & 2.5814 & 4.6286 & 0.9944 & 6 & 0.051 & - & - & - & - & - \\
\hline 8 & 2.3530 & 4.0457 & 0.9989 & 6 & 0.063 & 2.2961 & 3.7499 & 0.9890 & 7 & 0.066 \\
\hline 9 & 2.3844 & 4.0743 & 0.9928 & 6 & 0.051 & 2.4069 & 3.9090 & 0.9881 & 7 & 0.072 \\
\hline 10 & 2.1244 & 3.2743 & 0.9980 & 6 & 0.021 & 2.1861 & 3.4150 & 0.9936 & 7 & 0.046 \\
\hline 11 & 2.0604 & 3.1543 & 0.9992 & 6 & 0.013 & 2.1790 & 3.4027 & 0.9942 & 7 & 0.044 \\
\hline 12 & 2.1509 & 3.9671 & 0.9982 & 6 & 0.023 & 2.3737 & 3.9286 & 0.9824 & 8 & 0.099 \\
\hline 13 & 1.2978 & 2.8629 & 0.9981 & 6 & 0.018 & 1.2529 & 2.8292 & 0.9793 & 7 & 0.069 \\
\hline 14 & 1.5640 & 2.3200 & 0.9993 & 6 & 0.009 & 2.2704 & 4.4460 & 0.9835 & 6 & 0.086 \\
\hline 15 & 0.2332 & 0.6114 & 0.9209 & 6 & 0.027 & 0.7683 & 1.9354 & 0.8974 & 7 & 0.113 \\
\hline 16 & 1.6042 & 3.2971 & 0.9976 & 6 & 0.024 & - & - & - & - & - \\
\hline 17 & 1.5274 & 2.9086 & 0.9969 & 6 & 0.024 & - & - & - & - & - \\
\hline 18 & 2.2807 & 3.9200 & 0.9992 & 6 & 0.016 & 2.6382 & 4.7726 & 0.9933 & 6 & 0.058 \\
\hline
\end{tabular}

The lipophilicity determined experimentally $\left(\log k_{W}, R_{M}^{0}\right)$ in each case are higher for phenyl substituent (Table 3). The average of differences between the $R_{M}^{0}$ for these pairs of compounds (1, 2, 3 and 13, 14, 15) equal: 
for TLC methanol $\Delta=1.2914$ and acetonitrile $\Delta=0.8298$

for HPLC methanol $\Delta=0.5892$ and acetonitrile $\Delta=0.7666$.

The next group are compounds $\mathbf{4}$ - $\mathbf{7}$ and $\mathbf{1 6}$ - 18. The average of differences between the $R_{M}^{0}$ values obtained for methanol and acetonitrile for these compounds is $\Delta=0.9746$. The lowest $R_{M}^{0}$ values were obtained for compounds $\mathbf{4 , 6}$ and 16 (these substances have the lowest value of molecular weight) and the highest $R_{M}^{0}$ values were obtained for compounds $\mathbf{7}$ and $\mathbf{1 8}$. The compound $\mathbf{7}$ has the longest carbon chain of substituent $\mathrm{R}^{2}$ and the $\mathbf{1 8}$ has p-chlorophenyl substituent and the highest molecular weight.

In case the methanol-water system (in HPLC method) the highest $\log k_{W}$ value was obtained for $\mathbf{4}$, but in case of acetonitrile-water eluent the most lipophilic compound is $\mathbf{6}$. The compounds $\mathbf{8 , 9 , 1 0}$ and 12 have additional heterocyclic ring in their structure. There are most lipophilic substances among all analyzed compounds. The values of $\log k_{W}$ and $R_{M}^{0}$ from methanol-water system are higher than 3.2 and for acetonitrile are higher than 2.0. The most lipophilic compound of this group is $\mathbf{9}$ (Table 3).

The significant influence of used organic modifiers (methanol and acetonitrile) on the chromatographic lipophilicity parameters $\left(\log k_{W}, R_{M}^{0}\right)$ were observed. The values of $\log k_{W}, R_{M}^{0}$ for all compounds are higher for methanol-water chromatographic system than the acetonitrile-water system. As it is well known acetonitrile elution strength is smaller than methanol. Methanol and acetonitrile belong to two different groups of solvents based on the Snyder's selectivity triangle ${ }^{20}$. The methanol is in the second group and acetonitrile in the sixth. According to Karger at al ${ }^{21}$ the protondonor solubility parameter for methanol is high (acetonitrile does not have proton-donor properties) and the proton-acceptor solubility parameter is also much higher for methanol than for acetonitrile. Based on obtained results stronger affinity of 1,2,4-triazole derivatives to acetonitrile than to methanol were observed.

The slope ( $S$ ) from Eq. (1) and Eq. (2) is negative in all cases (Table 3), and it is suggested that the hydrophobic surface of the molecule interacts the non-polar adsorbent ${ }^{22}$. Generally the absolute value of the slope is lower for acetonitrile than for methanol as organic modifier of eluents. The lines of Eq. (1) and Eq. (2) are more steep for methanol-water mobile phase than for acetonitrile-water mobile phase.

As it is shown in Table 2 the concentration range for methanol or acetonitrile is not the same for all compounds. Therefore, a range of concentrations was selected (for methanol $45 \%-70 \%$ and for acetonitrile $25 \%-50 \%$, in both cases a concentration increased by 5\%) and missing values of $\log k$ (and $R_{M}$ ) were calculated by extrapolation on the basis of a linear equation. Selection of these intervals were performed in order to extrapolate it was always in the direction of lower concentrations of organic modifier.

As shown in Table 4 poor correlations between chromatographic lipophilicity parameters and computed $\log P$ values were obtained. The best correlations between the chromatographic lipophilicity parameter $\left(\log k_{W}\right.$ or $\left.R_{M}^{0}\right)$ and the calculated $\log P$ values were obtained for $\log P$ calculated by ALOGPS2.1 program. The high value of the correlation coefficient for relationships between the $P C 1 / \log k$ and $\varphi_{0}$ were observed for methanol and acetonitrile for HPLC method $(\mathrm{r} \geq 0,97)$ (see Table 4). Weaker correlations between $P C 1 / R_{M}$ and $\varphi_{0}$ were obtained for TLC methods $(\mathrm{r} \geq 0,80)$ than HPLC one. These results may indicate that the lipophilic interactions between the non-ionizable 1,2,4-triazole and 1,3,4-thiadiazole derivatives and stationary phases occur in this case ${ }^{23}$. Moreover in case of TLC method a high value of correlation coefficient $(\mathrm{r}=0,95)$ for relationships: $\log k_{m} v s . P C 2 / R_{M A C N}$ was obtained. This may indicate the presence of residual specific interactions between analyzed substances and adsorbent. 
Table 4. The correlation matrix concerning results obtained experimentally and theoretical lipophilicity parameters.

\begin{tabular}{|c|c|c|c|c|c|c|c|c|c|c|c|c|c|c|c|c|c|c|c|c|}
\hline & \multicolumn{10}{|c|}{ TLC } & \multicolumn{10}{|c|}{ HPLC } \\
\hline & $\begin{array}{l}5 \\
0 \\
5 \\
5 \\
5 \\
5 \\
0 \\
0\end{array}$ & us & $\begin{array}{l}T \\
0 \\
\sum^{2} \\
0 \\
\varphi\end{array}$ & $\frac{3}{3} \frac{3}{3}$ & 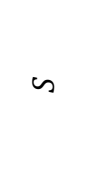 & 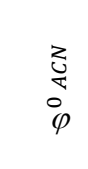 & 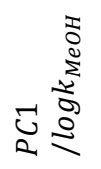 & 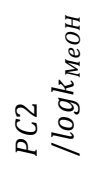 & ঢ心 & 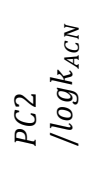 & 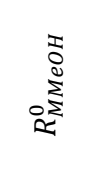 & $\omega$ & $\begin{array}{l}\pi \\
0 \\
\Sigma \\
\Sigma \\
\varphi\end{array}$ & 焉 & 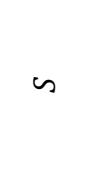 & 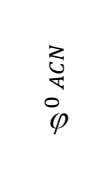 & ঢ̄ & $\stackrel{\substack{I \\
\Xi}}{\Sigma}$ & 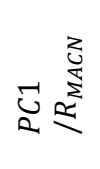 & Ũ \\
\hline milogP & 0.34 & -0.21 & 0.68 & 0.81 & 0.56 & 0.59 & 0.67 & 0.25 & -0.68 & 0.21 & 0.64 & 0.60 & 0.75 & 0.71 & 0.58 & 0.73 & -0.74 & 0.01 & 0.61 & -0.48 \\
\hline $\operatorname{clog} P$ & 0.39 & 0.07 & 0.43 & 0.58 & 0.29 & 0.55 & 0.48 & -0.04 & -0.62 & 0.17 & 0.61 & 0.60 & 0.52 & 0.68 & 0.61 & 0.54 & -0.62 & 0.18 & 0.46 & -0.53 \\
\hline ALOGPS & 0.40 & -0.16 & 0.71 & 0.79 & 0.46 & 0.69 & 0.71 & 0.17 & -0.76 & 0.19 & 0.64 & 0.61 & 0.66 & 0.70 & 0.57 & 0.69 & -0.78 & -0.03 & 0.63 & -0.46 \\
\hline$A C \log P$ & 0.45 & 0.05 & 0.54 & 0.65 & 0.32 & 0.62 & 0.58 & -0.03 & -0.68 & 0.20 & 0.62 & 0.60 & 0.57 & 0.67 & 0.58 & 0.58 & -0.68 & 0.10 & 0.51 & -0.49 \\
\hline ALOGP & 0.47 & -0.04 & 0.68 & 0.75 & 0.47 & 0.60 & 0.69 & 0.08 & -0.70 & 0.25 & 0.66 & 0.62 & 0.69 & 0.70 & 0.59 & 0.63 & -0.73 & 0.04 & 0.55 & -0.50 \\
\hline$M L O G P$ & 0.55 & 0.06 & 0.69 & 0.65 & 0.32 & 0.63 & 0.72 & -0.03 & -0.71 & 0.22 & 0.59 & 0.55 & 0.64 & 0.60 & 0.48 & 0.58 & -0.73 & -0.05 & 0.59 & -0.37 \\
\hline KOWWIN & 0.41 & 0.12 & 0.41 & 0.51 & 0.23 & 0.52 & 0.46 & -0.10 & -0.58 & 0.20 & 0.54 & 0.53 & 0.46 & 0.60 & 0.54 & 0.46 & -0.58 & 0.10 & 0.40 & -0.47 \\
\hline XLOGP2 & 0.53 & -0.01 & 0.73 & 0.76 & 0.45 & 0.63 & 0.75 & 0.05 & -0.72 & 0.24 & 0.66 & 0.61 & 0.75 & 0.66 & 0.51 & 0.69 & -0.79 & -0.04 & 0.66 & -0.40 \\
\hline XLOGP3 & 0.44 & -0.05 & 0.65 & 0.70 & 0.43 & 0.56 & 0.66 & 0.09 & -0.66 & 0.16 & 0.61 & 0.58 & 0.64 & 0.64 & 0.50 & 0.60 & -0.73 & -0.04 & 0.59 & -0.41 \\
\hline $\log P{ }_{C h S}$ & 0.49 & -0.07 & 0.75 & 0.80 & 0.59 & 0.51 & 0.75 & 0.14 & -0.64 & 0.25 & 0.63 & 0.56 & 0.80 & 0.57 & 0.38 & 0.72 & -0.77 & -0.08 & 0.71 & -0.27 \\
\hline $\log k_{W М е о H}$ & 1 & 0.70 & 0.60 & 0.49 & 0.10 & 0.52 & 0.74 & -0.66 & -0.64 & 0.42 & 0.79 & 0.79 & 0.64 & 0.55 & 0.48 & 0.39 & -0.72 & 0.53 & 0.46 & -0.41 \\
\hline$S$ & & 1 & -0.15 & -0.14 & -0.21 & -0.10 & 0.03 & -0.97 & -0.01 & 0.33 & 0.29 & 0.32 & -0.04 & 0.04 & 0.08 & -0.19 & -0.11 & 0.48 & -0.06 & -0.07 \\
\hline$\varphi_{0 \mathrm{MeOH}}$ & & & 1 & 0.80 & 0.32 & 0.84 & 0.98 & 0.17 & -0.89 & 0.16 & 0.76 & 0.71 & 0.91 & 0.70 & 0.56 & 0.74 & -0.86 & 0.18 & 0.71 & -0.47 \\
\hline $\log k_{W A C N}$ & & & & 1 & 0.76 & 0.60 & 0.81 & 0.22 & -0.74 & 0.48 & 0.81 & 0.78 & 0.90 & 0.78 & 0.69 & 0.79 & -0.82 & 0.36 & 0.59 & -0.62 \\
\hline$S$ & & & & & 1 & -0.05 & 0.33 & 0.36 & -0.13 & 0.70 & 0.34 & 0.33 & 0.49 & 0.28 & 0.26 & 0.43 & -0.38 & 0.08 & 0.19 & -0.23 \\
\hline$\varphi_{0} A C N$ & & & & & & 1 & 0.82 & 0.03 & -0.97 & -0.18 & 0.77 & 0.74 & 0.78 & 0.84 & 0.73 & 0.71 & -0.77 & 0.37 & 0.68 & -0.65 \\
\hline$P C 1 / \log k_{\mathrm{Mеон}}$ & & & & & & & 1 & 0.00 & -0.90 & 0.27 & 0.83 & 0.79 & 0.93 & 0.73 & 0.60 & 0.73 & -0.90 & 0.28 & 0.71 & -0.50 \\
\hline 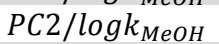 & & & & & & & & 1 & 0.04 & -0.21 & -0.25 & -0.29 & 0.10 & -0.05 & -0.10 & 0.22 & 0.05 & -0.48 & 0.09 & 0.10 \\
\hline$P C 1 / \log k_{A C N}$ & & & & & & & & & 1 & 0.00 & -0.88 & -0.86 & -0.88 & -0.90 & -0.79 & -0.77 & 0.87 & -0.45 & -0.72 & 0.71 \\
\hline$P C 2 / \log k_{A C N}$ & & & & & & & & & & 1 & 0.28 & 0.30 & 0.29 & 0.09 & 0.16 & 0.13 & -0.19 & 0.27 & -0.13 & -0.17 \\
\hline$R_{M M е O H}^{0}$ & & & & & & & & & & & 1 & 0.99 & 0.82 & 0.91 & 0.81 & 0.69 & -0.84 & 0.55 & 0.58 & -0.72 \\
\hline$S$ & & & & & & & & & & & & 1 & 0.75 & 0.91 & 0.83 & 0.64 & -0.79 & 0.59 & 0.51 & -0.75 \\
\hline$\varphi_{0 \mathrm{MeOH}}$ & & & & & & & & & & & & & 1 & 0.75 & 0.60 & 0.82 & -0.80 & 0.26 & 0.67 & -0.50 \\
\hline$R_{M A C N}^{0}$ & & & & & & & & & & & & & & 1 & 0.95 & 0.65 & -0.70 & 0.56 & 0.46 & -0.89 \\
\hline$S$ & & & & & & & & & & & & & & & 1 & 0.41 & -0.48 & 0.72 & 0.16 & -0.98 \\
\hline$\varphi_{0_{A C N}}$ & & & & & & & & & & & & & & & & 1 & -0.86 & -0.04 & 0.87 & -0.28 \\
\hline 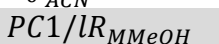 & & & & & & & & & & & & & & & & & 1 & 0.00 & -0.88 & 0.33 \\
\hline $\mathrm{PC} 2 / R_{\text {Ммеон }}$ & & & & & & & & & & & & & & & & & & 1 & -0.27 & -0.77 \\
\hline$P C 1 / R_{M A C N}$ & & & & & & & & & & & & & & & & & & & 1 & 0.00 \\
\hline$P C 2 / R_{M A C N}$ & & & & & & & & & & & & & & & & & & & & 1 \\
\hline
\end{tabular}


The eigenvalues and cumulative variance for $\log k$ and $R_{M}$ values were collected in Table 5 . The value of cumulative proportion for the first two principal components were compared. They explain $99,84 \%$ of variance in the case of acetonitrile as modifier, $99,47 \%$ of variance in the case of methanol (HPLC). In the case of TLC method these values are 98,70\% (for acetonitrile) and 97,77\% (for methanol). This is probably related to the precision of the measurements.

Table 5. Eigenvalues of the covariance matrix and cumulative proportion for logk and $R_{M}$ values.

\begin{tabular}{|c|c|c|c|c|}
\hline \multirow{3}{*}{ Principal component } & \multicolumn{4}{|c|}{$\log k$ (RP-HPLC) } \\
\hline & \multicolumn{2}{|c|}{ methanol } & \multicolumn{2}{|r|}{ acetonitrile } \\
\hline & Eigenvalue & Cumulative proportion & Eigenvalue & Cumulative proportion \\
\hline 1 & 5.821198 & 97.02 & 5.793624 & 96.56 \\
\hline 2 & 0.146959 & 99.47 & 0.196543 & 99.84 \\
\hline 3 & 0.020081 & 99.80 & 0.008055 & 99.97 \\
\hline 4 & 0.005947 & 99.90 & 0.001251 & 99.99 \\
\hline 5 & 0.003628 & 99.96 & 0.000314 & 100.00 \\
\hline \multirow[t]{2}{*}{6} & 0.002187 & 100.00 & 0.000214 & 100.00 \\
\hline & \multicolumn{4}{|c|}{$R_{M}(\mathrm{RP}-\mathrm{TLC})$} \\
\hline \multirow[t]{2}{*}{ Principal component } & \multicolumn{2}{|r|}{ methanol } & \multicolumn{2}{|r|}{ acetonitrile } \\
\hline & Eigenvalue & Cumulative proportion & Eigenvalue & Cumulative proportion \\
\hline 1 & 5.404420 & 90.07 & 5.116092 & 85.27 \\
\hline 2 & 0.461749 & 97.77 & 0.805870 & 98.70 \\
\hline 3 & 0.075111 & 99.02 & 0.046471 & 99.47 \\
\hline 4 & 0.046886 & 99.80 & 0.017871 & 99.77 \\
\hline 5 & 0.007521 & 99.93 & 0.007742 & 99.90 \\
\hline 6 & 0.004314 & 100.00 & 0.005954 & 100.00 \\
\hline
\end{tabular}

\section{Conclusions}

The lipophilicity of 1,2,4-triazole derivatives were obtained both chromatographically and by calculating methods. The linear correlation between retention parameter $\left(\log k, R_{M}\right)$ and the concentration of organic modifier were received using RP-HPLC and RP-TLC methods. The values of $\log k_{W}$ and $R_{M}^{0}$ are the retention parameters obtained for pure water by extrapolation. Based on the relationship between the structure of analyzed compounds and their retention parameters better results were obtained for TLC method than HPLC. The $\log k_{W}$ and $R_{M}^{0}$ values obtained are less for acetonitrile modifier than methanol in both chromatographic methods. A stronger affinity the 1,2,4-triazole and derivatives for acetonitrile than for methanol were observed.

The best correlations between the chromatographic indices of lipophilicity and calculated by ALOGPS 2.1 program were obtained. The $P C 1 / \log k$ (or $P C 1 / R_{M}$ ) and $\varphi_{0}$ parameters are most suitable for the assessment of lipophilicityof the 1,2,4-triazole derivatives.

\section{Experimental}

\subsection{Materials}

1,2,4-triazole derivatives (Table 1) were synthesized in the laboratory at the Department of Organic Chemistry in Medical University of Lublin. Two binary solvent systems: methanol-water and acetonitrile-water were used. Solvents (methanol and acetonitrile) were LiChrosolv (Merck, Darmstadt, Germany) for liquid chromatography grade and bidistilled water was used as the diluter. 


\subsection{High-performance liquid chromatography}

All HPLC experiments were performed by use of chromatograph equipped with Elite LaChrom L2130 gradient pump (Hitachi-Merck, Darmstadt, Germany), SPD-10AVP UV-VIS detector (Shimadzu, Kyoto, Japan) and Rheodyne $7725 \mathrm{i}$ valve with $20 \mu \mathrm{l}$ loop at ambient temperature. Standards were applied into the chromatographic column (RP-18 Waters Symmetry column, $15 \mathrm{~cm}$ length, $4.6 \mathrm{~mm}$ i. d., $5 \mu \mathrm{m}$ particle size) by use of Hamilton (Hamilton, Bonaduz, Switzerland) syringe. Mobile phases were degassed by use of built-in membrane degasser.

$20 \mu \mathrm{l}$ of each standard $(0,1 \%$ solutions $)$ was applied into the chromatographic column and chromatograms were developed at flow rate $1.0 \mathrm{~mL} \cdot \mathrm{min}^{-1}$ in isocratic mode using various concentrations of modifier in binary polar mobile phases (methanol-water: 55 - 80\% (v/v), acetonitrilewater: 40 - 80\% (v/v), in both cases,the concentrationincreasedby 5\%).

Chromatograms were detected at 254nm. All experiments were repeated triplicate and the final results were its arithmetic mean. Dead time was measured for uracil (Calbiochem - Merck, Darmstadt, Germany).

\subsection{Thin Layer Chromatography}

Thin-layer chromatography was performed on 10x10cm TLC plates coated with RP-18254 using methanol-water and acetonitrile-water mixtures as mobile phase (Table II). 0,5\% ofthe solutions wereappliedto the plates and they were developed to a distance of $9 \mathrm{~cm}$ at room temperature in a horizontal chambers DS II (Chromdes, Lublin, Poland). After drying the chromatograms were visualized at a wavelength of 254nm. Each experiment was performed three time.

\subsection{Log P calculation}

$\boldsymbol{m i} \log \boldsymbol{P}$ values were calculated using $\boldsymbol{m i} \log \boldsymbol{P} 1.2$ software $^{15}, \boldsymbol{c} \boldsymbol{l o g} \boldsymbol{P}$ parameter was calculated using OSIRIS Property Explorer ${ }^{16}$ and the ALOGPS, AClogP, AlogP, MLOGP, KOWWIN, XLOGP2, XLOGP3 values were calculated using $\boldsymbol{A L O G P S} 2.1$ program ${ }^{17}$. The $\log P_{\text {Chs }}$ parameter were calculated by ACD/ChemSketch Freeware (http://www.acdlabs.com).

\subsection{PCA calculations}

The necessary calculations were performed using Microsoft Excel 2002. The PCA analysis were facilitated using the Pooptools ${ }^{\mathrm{TM}}$ program ${ }^{24}$.

\section{Acknowledgement}

The authors would like to thank the anonymous referees for constructive comments on earlier version of this paper.

\section{References}

1. Ertl P., Rohde B., and Selzer P. (2000) Fast calculation of molecular polar surface area as a sum of fragment-based contributions and its application to the prediction of drug transport properties. $J$. Med. Chem., 43, 3714-3717.

2. Hansch C., and Fujita T. (1964) $p-\sigma-\pi$ Analysis. A Method for the Correlation of Biological Activity and Chemical Structure. J. Am. Chem. Soc., 86, 1616-1626.

3. Komsta Ł., Skibiński R., Berecka A., Gumieniczek A., Radkiewicz B., and Radoń M. (2010) Revisiting thin-layer chromatography as a lipophilicity determination tool-a comparative study on several techniques with a model solute set. J. Pharm. Biomed. Anal., 53, 911-918. 
4. Pitucha M., Polak B., Swatko-Ossor M., Popiołek Ł., and Ginalska G. (2010) Determination of the Lipophilicity of Some New Derivatives of Thiosemicarbazide and 1,2,4-triazoline-5-thione with Potential Antituberculosis Activity. Croat. Chem. Acta, 83, 299-306.

5. Plech T., Luszczki J.Ł., Wujec M., Flieger J., and Pizoń, M. (2013) Synthesis, characterization and preliminary anticonvulsant evaluation of some 4-alkyl-1,2,4-triazoles. Eur. J. Med. Chem., 60, 208-215.

6. Briciu R.D., Kot-Wąsik A., Wąsik A., Namieśnik J., and Sărbu C. (2010) The lipophilicity of artificial and natural sweeteners estimated by reversed-phase thin-layer chromatography and computed by various methods. J. Chromatog. A, 1217, 3702-3706.

7. Casoni D., Kot-Wąsik A., Namieśnik J., and Sărbu C. (2009) Lipophilicity data for some preservatives estimated by reversed-phase liquid chromatography and different computation methods. J. . Chromatogr. A, 1216, 2456-2465.

8. Snyder L.R., Dolan J.W., and Gant J.R. (1979) Gradient elution in high-performance liquid chromatography: I. Theoretical basis for reversed-phase systems. J. Chromatogr. A, 165, 3-30.

9. Soczewiński E., and Wachtmaister C.A. (1962) The relation between the composition of certain ternary two-phase solvent systems and $R_{M}$ values. J. Chromatogr., 7, 311-320.

10. Jóźwiak K., Szumiło H., and Soczewiński E. (2001) Lipophilicity, methods of determination and its role in biological effect of chemical substances. Wiadomości Chemiczne (in Polish), 55, 10471074.

11. Valko K., and Slegel P. (1993) New chromatographic hydrophobicity index $\left(\phi_{0}\right)$ based on the slope and the intercept of the log $k^{\prime}$ versus organic phase concentration plot. J. Chromatogr., 631, 49-61.

12. Pyka A. (2004) Study of lipophilicity and application of selected topological indexes in QSAR analysis of nicotinic acid derivatives. Part I. J. Planar Chromatogr., 17, 275-279.

13. Popiołek Ł., Kosikowska U., Mazur L., Dobosz M., and Malm A. (2013) Synthesis and antimicrobial evaluation of some novel 1,2,4-triazole and 1,3,4-thiadiazole derivatives; Med. Chem. Res., 22, 3134-3147.

14. Popiołek Ł., Kosikowska U., Dobosz M., and Malm A. (2012) Synthesis and Antimicrobial Properties of New Thiosemicarbazide, 1,2,4-Triazole, and 1,3,4-Thiadiazole Derivatives of Sulfanylacetic Acid. Phosphorus, Sulfur, and Silicon Relat. Elem., 187, 468-481.

15. www. molinspiration.com

16. www.organic-chemistry.org

17. www.vcclab.org

18. Ertl P. (2010) Molecular structure input on the web. J. Cheminform., 2, 1-9.

19. Jaffe H.H. (1953) A Reexamination of the Hammet Equation. Chem. Rev., 53, 191-238.

20. Snyder L.R. (1978) Classification of the Solvent Properties of Common Liquids. J. of Chromatogr. Sci., 16, 223-234.

21. Karger B.L., Snyder L.R., and Econ C. (1976) An expanded solubility parameter treatment for classification and use of chromatographic solvents and adsorbents : Parameters for dispersion, dipole and hydrogen bonding interactions. J. Chromatogr., 125, 71-88.

22. Cimpan G., Hadaruga M., and Miclaus V. (2000) Lipophilicity characterization by reversedphase liquid chromatography of some furan derivatives. J. Chromatogr. A, 869, 49-55.

23. Casoni D., Cobzac C.S., and Sarbu C. (2010) A comparative study concerning the lipophilicity of some synthetic dyes estimated by thin layer chromatography and different computation methods.Rev. Chim., 61, 229-234.

24. Hood G.M. (2010) PopTools version 3.2.5. Available on the internet. URL, http://www.poptools.org. 